Рахимов Равиль Зуфарович (Казань). Доктор технических наук, профессор, член-корреспондент РААСН. Профессор кафедры строительных материалов ФГБОУ В0 «Казанский государственный архитектурно-строительный университет» (420043, Республика Татарстан, Казань, ул. Зелёная, 1. КазГАСУ).

Rakhimov Ravil Z. (Kazan). Doctor of Technical Sciences, Professor, Corresponding Member of RAACS. Professor of the Department of Building Materials at the Kazan State University of Architecture and Engineering (1 Zelenaya St, Kazan, 420043. KSUAE).

(-) Рахимов Р.3., 2021

Academia. Архитектура и строительство, № 4, стр. 120-124.

\title{
Гипс в строительстве с древних веков до современности
}

\section{Р.3.Рахимов, КазГАСУ, Казань}

Гипсовые вяжущие вещества и материалы на их основе являются одними из первых искусственных минеральных строительных материалов, которые были получены в истории человеческой цивилизации и нашли применение в строительстве с эпохи Древнего мира до настоящего времени. Строительный гипс, ангидритовые и гипсоангидритовые вяжущие индивидуально или в сочетании с известью, минеральными и химическими добавками применялись до нашей эры, в эпоху средневековья и возрождения и вплоть до XX века в качестве кладочных, штукатурных и отделочных растворов. В VII-VIII столетиях применение гипса в строительстве, забытое в начале нашей эры после распада Римской империи, пережило первое возрождение в Европе. XX век стал эпохой второго возрождения гипса в строительстве, но уж не только в Европе, а в везде мире. Сырьевые возможности гипсовых вяжущих и материалов на их основе и уровень достижений научных исследований и разработок России позволяет ей занять ведущее место в мире по производству и применению их в строительстве.

Ключевые слова: минеральное сырье, гипс, ангидрит, вяжущее, раствор.

\section{Gypsum from Ancient Times to the Present}

\section{R.Z.Rakhimov, KSUAE, Kazan}

Gypsum binders and materials based on them are one of the first man-made mineral building materials that were obtained in the history of human civilization and found application in building construction from ancient world to the present. Building gypsum, anhydrite and gypsum-anhydrite individually or combined withlime, minerals and chemical additions were used $B C E$, in the mediaeval and renaissance and to XX century as masonry and plastering mortars. In VII-VIII centuries gypsum application experienced a revival in Europe forgotten in the beginning of our era after the collapse of the Western Roman Empire. XX century is epoch of second renaissance of gypsum in building construction not only in Europe but also in the whole world. Commodity-related opportunities of gypsum binders and materials based on them and scientificlevel of achievements in Russia allow to takeleadership position in the world on the production and application in building construction.

Keywords: raw materials, gypsum, anhydrite, binder, mortar.

Гипсовые вяжущие вещества являются одними из первых искусственных вяжущих веществ, которые были получены в истории человеческой цивилизации и нашли применение в строительстве с эпохи Древнего мира до настоящего времени. Их получают обжигом гипсового камня и последующим помолом. Гипсовый камень образовался в результате испарения мирового океана 150-200 млн лет назад и встречается в виде двуводного и безводного сульфата кальция - гипса и ангидрита. По разным сведениям, впервые гипсовые вяжущие были получены и стали применяться в строительстве в различных регионах мира в период с XI по V тысячелетие до н. э. В наибольших объёмах они нашли применение в виде строительного полуводного гипса, получаемого обжигом при температуре $130-180{ }^{\circ} \mathrm{C}$, в III-II тысячелетиях до н. э. - в виде штукатурных, кладочных и отделочных раство-

${ }^{1}$ Все изображения взяты из открытых источников сети Интернет.

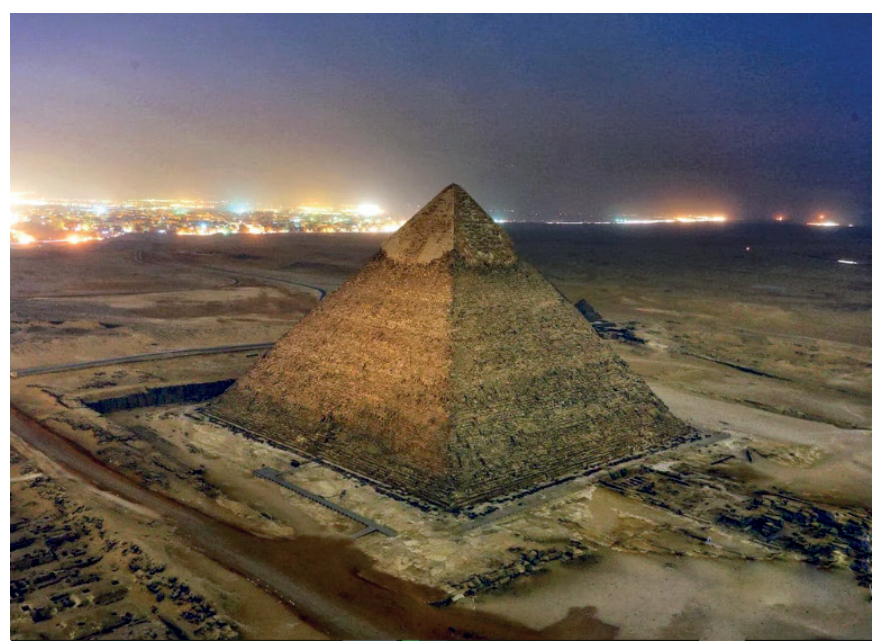

Puс. 1. Пирамида Хеопса. Ezunem ${ }^{1}$ 
ров. Особенно высоким качеством обладали кладочные гипсовые растворы и штукатурка в пирамиде Хеопса (рис. 1) и гробнице его матери, в которой содержание гипса составляет 97,3- 9,5\%.

C III тысячелетия до н. э. строительный гипс применялся в глиногипсовых, гипсоглиняноизвестковых и гипсоизвестковых кладочных и штукатурных растворах. В I тысячелетии до н. э., в частности, был построен в городе Мосул дворец Саргона (рис. 2), который имел более 200 помещений, оштукатуренных гипсоизвестковыми растворами.

В отдельных регионах мира с III тысячелетия до н.э. нашли применение ангидритовые вяжущие, получаемые обжигом двуводного гипса и ангидрита при различных температурах. Нашло применение и двухфазное гипсовое вяжущее, состоящее из полуводного гипса и растворимого ангидрита, получаемого при обжиге гипсового камня при температуре 300-400 ${ }^{\circ} \mathrm{C}$. Это вяжущее с более высокой прочностью и удлинёнными сроками схватывания с полуводным гипсом получило распространение для штукатурных, кладочных растворов и наливных полов, которые применяются в отдельных регионах мира и до настоящего времени.

В середине III тысячелетия до н. э. в городе МохенджоДаро в Индии стены некоторых зданий покрывались свет-

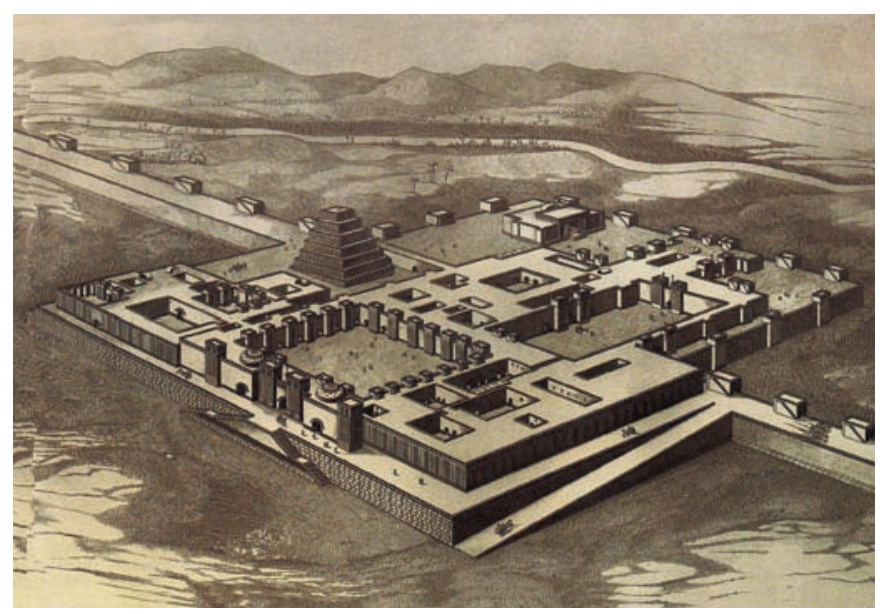

Рис. 2. Дворец Саргона в Дур-Шаррукине, столище Ассирии

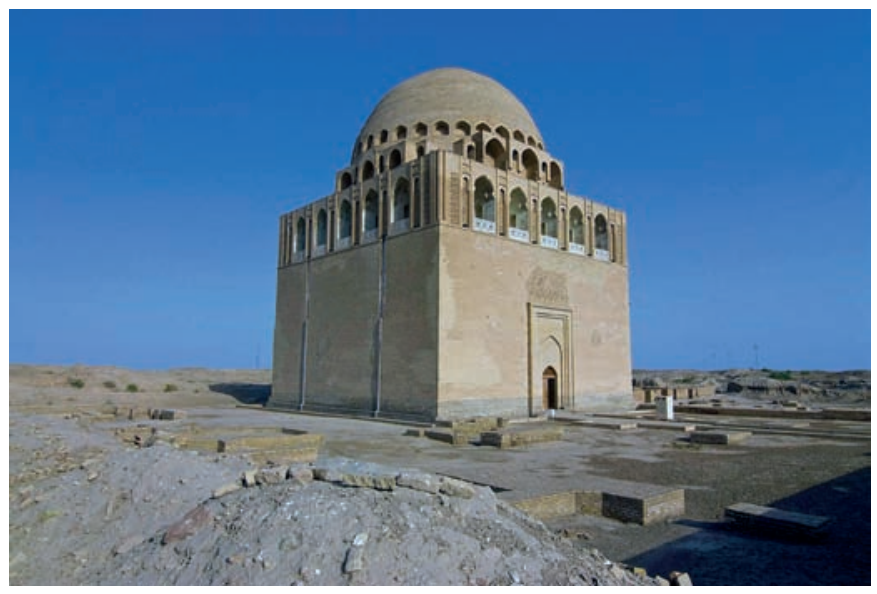

Рис. 3. Мавзолей султана Санджара. Туркменистан ло-серым гипсовым раствором с добавками песка, глины и известковой муки.

Со II тысячелетия до н. э. в Индии в строительстве применялся преимущественно высокообжиговый гипс, получаемый обжигом природных гипса или ангидрита при температурах 800-950 드, который от ранее упомянутых гипсовых вяжущих отличается повышенной водостойкостью и применялся в гипсоглиняных, гипсоглиняноизвестковых и гипсоизвестковых кладочных и штукатурных растворах в различных зданиях и сооружениях, в том числе гидротехнических. В тот период высокообжиговый гипс называли гидравлическим, хотя на самом деле он не соответствовал современным требованиям к гидравлическим минеральным вяжущим веществам.

С конца первой половины I тысячелетия до н. э. и до начала второй половины I тысячелетия н. э. широкое применение в строительстве в Древней Греции и Древнем Риме получил строительный гипс, использовавшийся преимущественно для оштукатуривания и отделки внутренних стен и колонн в виде гипсовых и гипсоизвестковых растворов, в отдельные разновидности которых вводился измельчённый в пыль мрамор (такие растворы назывались «стук»). В этот же период времени в Древней Греции и Древнем Риме к гипсовому вяжущему добавляли мраморный порошок в сочетании с кварцами и клеями, получая при этом искусственный мрамор для изготовления архитектурных деталей и статуй.

В эпоху Средневековья и Возрождения многие выдающиеся памятники строительного искусства были построены с использованием гипсовых, глиногипсовых и гипсоизвестковых вяжущих в кладочных, штукатурных и отделочных растворах. От незначительного в эпоху Древнего мира до широкого c V века увеличилось применение гипсовых вяжущих в Средней Азии, Закаспии, Закавказье, городе Болгари, Мексике. В Средней Азии и на Кавказе в монументальном и гражданском строительстве в виде вяжущего использовались разновидности глиногипса - «ганч», «гажа» и «азрык», подвергнутые обжигу при температуре $130-170{ }^{\circ} \mathrm{C}$. С применением кладочного и штукатурного раствора на их основе в Старом Мерве (Туркмения) в XII веке были построены мавзолей султана Санджара (рис. 3), мост через реку Мургаб; бани в Бухаре, эксплуатируемые до настоящего времени.

С начала XV века большинство жилых домов центрального города ацтеков Теночтитлана (около современного Мехико), выстроенных из сырцового кирпича, были покрыты гипсовой штукатуркой ослепительной белизны.

В Европе забытая в начале нашей эры после распада Римской империи практика применения гипса в строительстве переживает первое возрождение в период VII-VIII веков в виде эстрих-гипса, а с X-XII веков - строительного гипса, гипсовых и смешанных штукатурных и кладочных растворов. Широкое применение гипса в Средние века получило в Европе, когда его активное производство наладили во Франции, используя крупное месторождение гипса, расположенное вблизи 130-метрового холма Монмартр в Париже. Половина 
зданий, построенных в Париже в эпохи Средневековья и Возрождения, воздвигнуты на гипсовых растворах. В Германии с использованием гипсовых растворов в этот период времени строились замки, городские стены, церкви, в том числе Бенедиктинский монастырь в Люксембурге (рис. 4).

В Англии в XIV веке гипс использовался для оштукатуривания стен и каминных полок в Виндзорском замке (рис. 5).

С ростом объёмов строительства в мире с XVII-XVIII веков в отдельных объёмах, уступающим объёмам известь содержащих вяжущих, увеличилось потребление гипсовых вяжущих в части штукатурных растворов, устройства монолитных полов, отделке и производстве архитектурных деталей. В этот период большинство зданий, например, в Тбилиси было построено с применением глиногипса «гажа». Его применение было распространено на Кавказе в целом, в Закавказье и Закаспии. В это же время получило продолжение и расширение применение другой разновидности глиногипса - «ганча» в Средней Азии, Узбекистане (рис. 6), Киргизии, Туркменистане и др.

В этот же период времени отдельно или в смеси с известью гипсовые вяжущие применялись и в России, в частности, при строительстве Свято-Троицкого монастыря в Муроме (рис. 7).

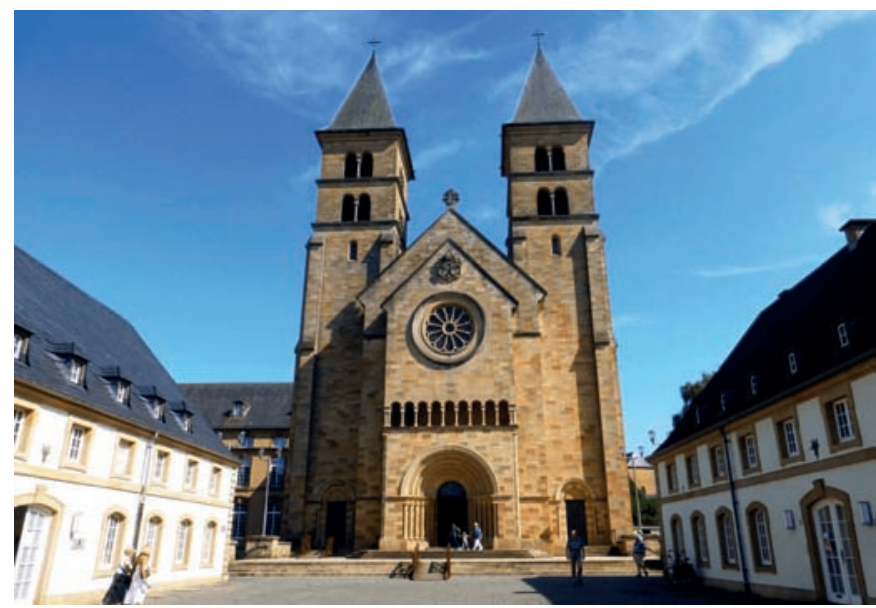

Рис. 4. Бенедиктинский монастырь. Люксембург

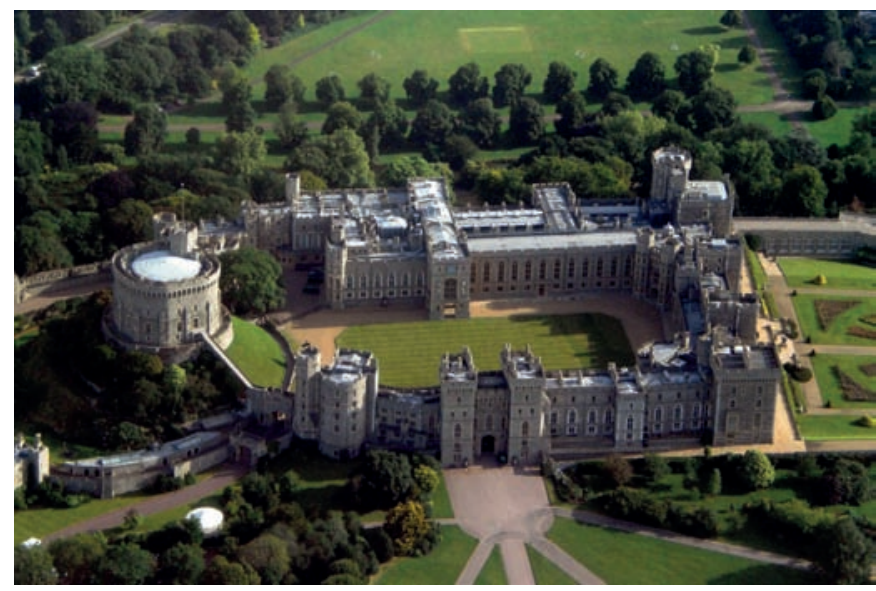

Рис. 5. Виндзорский замок. Великобритания
B XVIII-XIX веках гипс использовался в казённом и дворцовом строительстве в Санкт-Петербурге, во внутренней отделке каменных зданий в Рижской, Казанской, Нижегородской и Архангельской губерниях.

С древних времён и до начала XVIII века знания о минеральных вяжущих веществах, в том числе гипсовых, формировались на основе данных производства и применения и не имели научного обоснования и научной интерпретации. Подлинные научные исследования в области гипсовых вяжущих начались с созданием физико-химических исследований. В 1768 году французский естествоиспытатель А. Лавуазье установил, что твердение обожжённого гипса основано на взаимодействии его с водой. В первой четверти XIX века первые теоретические представления о гипсовых вяжущих были развиты: в России учёными М. Двигубским, В. Севергиным, А. Потылициным, М. Глазенапом; в Германии - учёными 0. Флерке, Я. Левинским. B XVIII-XIX века во многих странах (Германия, Россия и др.) для отделки различных сооружений применялся высокопрочный гипс, получаемый при автоклавной обработке гипсового камня. В этот период применение гипсовых вяжущих в строительстве значительно сократилось в связи с развитием производства гидравлической извести,

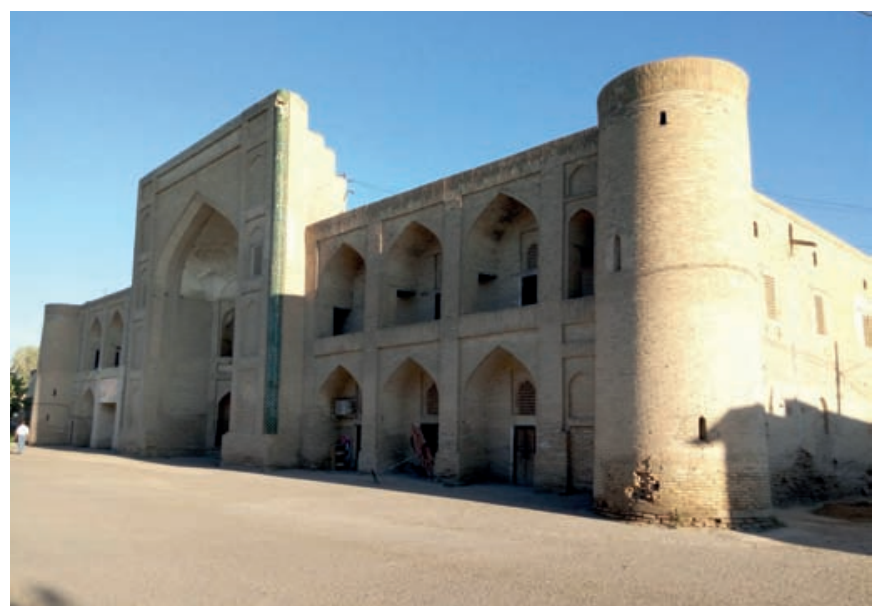

Рис. 6. Медресе Джуиборий Калон. Бухара, Узбекистан

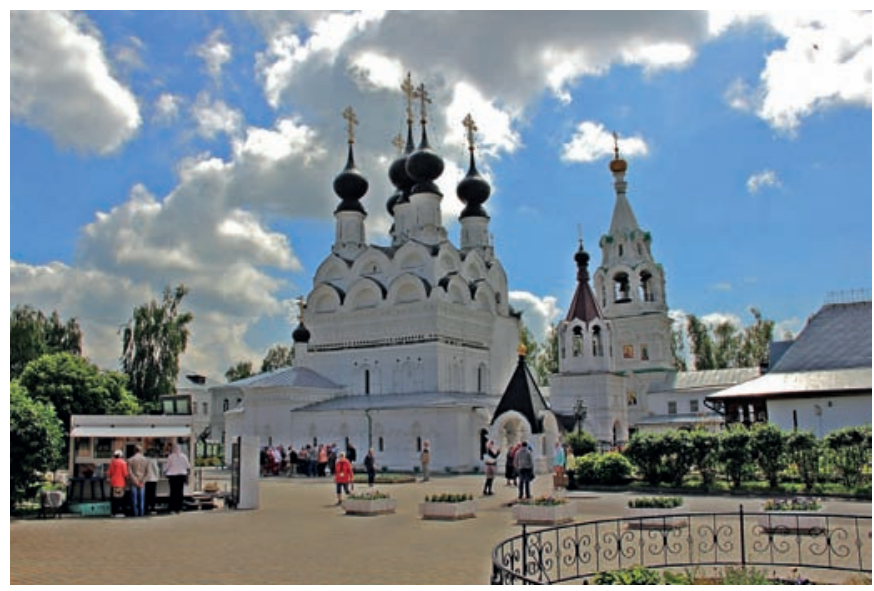

Рис. 7. Свято-Троицкий монастырь. Муром, Владимирская область 
романцемента и портландцемента, отличающихся повышенными и высокими прочностью и водостойкостью.

$\mathrm{XX}$ век явился эпохой второго возрождения использования гипсовых вяжущих, но уже не только в Европе, а во всём мире. По утверждению западных специалистов, расширение производства и применения гипсовых вяжущих и материалов на их основе позволило с середины XX века их странам добиться революционныхуспехов в энергосбережении, охране окружающей среды и повышении производительности труда в строительстве и промышленности строительных материалов. В течение XX века производство гипсовых вяжущих и материалов и применение их в строительстве возросло в целом мире и отдельных странах в десятки раз. Эта тенденция сохранилась и в первые двадцать лет XXI века - наращивание объёмов производства гипсовых вяжущих, материалов и изделий на их основе в последние десятилетия значительно опережают другие, применение гипсовых материалов и изделий на единицу объёма строительной продукции выросло: в США - в 2,5 раза, в Японии - в 1,8 раза. В целом высокий рост применения гипсовых материалов начался с производства в больших объёмах гипсокартона, разработанного и запатентованного американским инженером А. Саккетом в начале XX века. Разработанный гипсокартон на 91,1\% состоит из полуводного гипса и соответствует требованиям современных стандартов. США до настоящего времени производит более $40 \%$ всего мирового производства. Мировая добыча природного гипса в настоящее время составляет около 110 млн тонн. Например, в Китае с 1990 по 2010 год добыча гипса выросла с 8074 тыс. до 36559 тыс. тонн. В последние годы в Китае добывают около 37\% от мировой добычи гипса, в США - около 20\%, в Европе - около 12\%, в России - около 6\%.

Второе возрождение применения гипсовых вяжущих и материалов на их основе в строительстве связано с систематическими научными исследованиями и практическими разработками в XX веке в области гипсовых вяжущих и материалов с повышенными и высокими прочностью и водостойкостью.

По сравнению с другими минеральными вяжущими вяжущие на основе сульфата кальция имеют ряд особенностей. Они характеризуются короткими сроками схватывания и твердения и, следовательно, быстрым техническим процессом; хорошей формуемостью и удобоукладываемостью, равномерностью изменения объёма при твердении и отсутствием необходимости уплотнения, образованием благоприятной пористой или капиллярной структуры, позволяющей регулировать влажность (положительное влияние на микроклимат в помещении), незначительной плотностью и, как следствие, повышенной теплоизоляционной способностью; высокой огнестойкостью, благоприятным поведением при высыхании, низкой равновесной влажностью, хорошей обрабатываемостью; небольшими производственными затратами. Затраты топлива и электроэнергии на производство одной тонны гипсового вяжущего соответственно в 4,5 раза и 4,9 раза меньше, чем у портландцемента.
Значительные достижения в разработке научных основ получения и производства композиционных гипсовых вяжущих с повышенными и высокими прочностью и водостойкостью принадлежат советским и российским учёным П. Будникову, А. Волженскому, И. Передерию, П. Боженову, А. Ферронской, В. Коровякову, А. Бурьянову, В. Белову; научным школам МГСУ (МИСИ), ВНИИСТРОМа, КазГАСУ и др. Исследования и разработки зарубежных и отечественных учёных, выполненные в XX веке в области гипсовых вяжущих и материалов на их основе, привели к тому, что к половине этого столетия номенклатура гипсовых материалов, выпускаемых в мире, стала чрезвычайно широкой: гипсовые вяжущие - строительный, высокопрочный, формовочный, отделочный, медицинский гипс; ангидритовый и гипсоангидритовые, гипсоцементнопуцелановые, известково-гипсозольные, известково-гипсопуццолановые, многофазовые, композиционные, низкой водопотребности вяжущие; штукатурные, шпаклёвочные, монтажные, для устройства полов сухие строительные смеси; плиты, профильные и малые архитектурные изделия для внутренней отделки зданий, получаемые распировкой и обработкой природного гипсового камня; стеновые и перегородочные плиты и камни, прессованный кирпич, панели гипсобетонные для перегородок, прокатные панели для пола размером на комнату, блоки и панели наружных стен, подоконные доски, санитарнотехнические кабины, вентиляционные блоки, крупные элементы объёмно-блочного домостроения, панели перекрытий и покрытий; отделочные, декоративные, акустические, огнезащитные материалы и изделия - листы гипсокартонные, гипсоволокнистые и гипсостружечные для внутренней отделки; мраморовидные плиты, плафоны и карнизы; теплоизоляционные плиты и изделия - пеногипсоволокнистый и пенополимергипсовый утеплитель; теплоизоляционные скорлупы для теплоизоляции трубопроводов в системах отопления, горячего водо- и пароснабжения жилых, культурно-бытовых и промышленных зданий.

Общий мировой разведанный запас гипсовых месторождений составляет около 7,5 млрд тонн, из которых более половины расположены на территории России. Запасы природного гипса России в пять раз больше таковых в США. Значительный гипсовый сырьевой ресурс в различных регионах мира, в том числе и в России, составляют гипсосодержащие побочные продукты и отходы промышленности - энергогипс, фосфогипс, борогипс и др. Ежегодный объём их образования в мире превышает 150 млн тонн. В ряде стран производство и применение гипсовых вяжущих достигает 20-27 \% от общего объёма производства и применения минеральных вяжущих веществ. Сырьевые возможности гипсовых вяжущих и материалов на их основе и уровень достижений научных исследований и разработок России позволяют ей занять ведущее место в мире по производству и применению их в строительстве.

\section{Лuтература}

1. Значко-Яворский, И.Л. Очерки истории вяжущих веществ от древнейших времен до середины XIX века / И.Л. Значко-Яворский. - М. : Изд-во АН СССР, 1963. - 496 с. 
2. Потапова, E.H. История развития вяжущих материалов : Учебное пособие для вузов / Е.Н. Потапова. - СПб : Лань, 2016. - 151 c.

3. Schwiefe, H.E. Alte bund neue Ezkentnisse in der Hertsfellund and Anwendung der Gipse / H.E. Schwiefe, A.N. Knauf. - Berlin, 1968.

4. Bruckner, H.P. Der Baustoff Gips / H.P. Bruckner, T. Dchler, G. Fietsch // Stoffliche Grundlagen. Herstellung von Gipsbauelementen. - Berlin, 1978.

5. Будников, П.П. Гипс, его исследование и применение / П.П. Будников. - М.; Л. : Государственное издательство строительной литературы, 1943. - 372 с.

6. Волженский, А.В. Минеральные вяжущие вещества. Технология и свойства : Учебник / А.В. Волженский; 4-е изд. переработанное и дополненное / М. : Стройиздат, 1986. $-463 \mathrm{c}$.

7. Гордашевский, П.Ф. Производство гипсовых вяжущих материалов из гипсосодержащих отходов / П.Ф Гордашевский, А.В. Долгарев. - М. : Стройиздат, 1987. - 105 с.

8. Гипсовые материалы и изделия (производство и применение) : Справочник / Под общей редакцией А.В. Ферронской. - М. : АСВ, 2004. - 485 с.

9. Рахимов, Р.3. Состояние и тенденции развития промышленности гипсовых строительных материалов / Р.3. Рахимов, М.И. Халиуллин // Строительные материалы. - 2010. - № 2. - С. 44-46.

10. Рахимов, Р.3. Строительство и минеральные вяжущие вещества прошлого, настоящего и будущего / Р.3. Рахимов, Н.Р. Рахимова // Строительные материалы. - 2013. - № 5 - С. 57-59.

11. Гипс его использование и применение // Материалы международной научно-практической конференции. Под редакцией А.Ф. Бурьянова и И.В. Бессонова / М. : Реклама и продвижение, 2015.

\section{Referernces}

1. Znachko-Yavorskii I.L. Ocherki istorii vyazhushchikh veshchestv ot drevneishikh vremen do serediny XIX veka [Essays on the history of binders from ancient times to the middle of the 19th century]. Moscow, Publishing house of the Academy of Sciences of the USSR, 1963, $496 \mathrm{p}$.

2. Potapova E.N. Istoriya razvitiya vyazhushchikh materialov [The history of the development of binders. Textbook for universities]. Saint Petersburg, Lan Publ., 2016, 151 p.

3. Schwiefe H.E., Knauf A.N. Alte bund neue Ezkentnisse in der Hertsfellund and Anwendung der Gipse / Berlin. 1968.

4. Bruckner H.P., Dchler T., Fietsch G. Der Baustoff Gips. In: Stoffliche Grundlagen. Herstellung von Gipsbauelementen. Berlin, 1978.

5. Budnikov P.P. Gips, ego issledovanie i primenenie [Gypsum, its research and application]. Moscow, Stroiizdat Publ., 1951, 372 p.

6. Volzhenskii A.V. Mineral'nye vyazhushchie veshchestva. Tekhnologiya i svoistva [Mineral binders. Technology and properties]. Moscow, Stroiizdat Publ., 1979, 463 p.

7. Gordashevskii P.F., Dolgarev A.V. Proizvodstvo gipsovykh vyazhushchikh materialov iz gipsosoderzhashchikh otkhodov [Production of gypsum binders from gypsum-containing waste]. Moscow, Stroiizdat Publ., 1987, 105 p.

8. Ferronskaya A.V. (ed.). Gipsovye materialy i izdeliya (proizvodstvo i primenenie). Spravochnik [Gypsum materials and products (production and use). Directory]. Moscow, ASV Publ., 2004, 485 p.

9. Rakhimov R.Z., Khaliullin M.I. Sostoyanie i tendentsii razvitiya promyshlennosti gipsovykh stroitel'nykh materialov [State and development trends of the gypsum building materials industry]. In: Stroitel'nye materialy, 2010, no. 2, pp. 44-46.

10. Rakhimov R.Z., Rakhimova N.R. Stroitel'stvo i mineral'nye vyazhushchie veshchestva proshlogo, nastoyashchego i budushchego [Construction and mineral binders of the past, present and future]. In: Stroitel'nye materialy, 2013, no. 5, pp. 57-59.

11. Gips ego ispol'zovanie i primenenie [Gypsum, its use and application]. In: Materialy mezhdunarodnoi nauchnoprakticheskoi konferentsii [Materials of the international scientific and practical conference]. A.F. Bur'yanov and I.V. Bessonov (eds.). Moscow, Reklama i prodvizhenie Publ., 2015. 